\title{
Contrast-Enhancing Meningeal Lesions Are Associated with Longer Survival in Breast Cancer-Related Leptomeningeal Metastasis
}

\author{
Anne Constanze Regierer ${ }^{\mathrm{a}} \quad$ Andrea Stroux $^{\mathrm{b}}$ Dagmar Kühnhardt ${ }^{\mathrm{a}} \quad$ Annette Dieing $^{\mathrm{a}}$ \\ Silvia Lehenbauer-Dehm ${ }^{a}$ Bernd Flath ${ }^{c}$ Kurt Possinger ${ }^{\mathrm{a}}$ Jan Eucker ${ }^{\mathrm{a}}$ \\ ${ }^{a}$ Abteilung für Onkologie und Hämatologie, \\ ${ }^{b}$ Abteilung für Biometrie und Klinische Epidemiologie, Charité Universitätsmedizin Berlin, \\ ${ }^{\mathrm{c}}$ Hämatologisch-onkologische Praxis Altona, Hamburg, Germany
}

\section{Key Words}

Breast cancer - Leptomeningeal metastases .

Carcinomatous meningitis - Neoplastic meningitis . Intrathecal chemotherapy

\section{Summary}

Background: Leptomeningeal metastasis (LM) is a devastating complication of advanced cancer. Despite aggressive therapy survival is very poor. Methods: Data of all breast cancer patients with LM were retrospectively analyzed ( $n=27$ ). Results: Median survival was 9 weeks. Patients with contrast-enhancing meningeal lesions $(n=11)$ detected by MRI had a median survival of 33 weeks versus 8 weeks for patients without contrast-enhancing lesions ( $n=9$; $p=0.0407$ ). Patients who received systemic chemotherapy ( $n=18$ ) had a median survival of 15 weeks versus 7 weeks $(n=9 ; p=0.0106)$. Patients undergoing radiotherapy $(n=8)$ had a median survival of 17 weeks as compared to 5 weeks for patients without radiotherapy ( $n=18 ; p=0.0188$ ). In a multiple Cox regression analysis, lack of systemic therapy (hazard ratio, HR 89.5; $p=0.002$ ) and negative hormone receptor status (HR 4.2; $p=0.027$ ) emerged as significant main risk factors, together with contrast-enhancing lesion as effect modifier for systemic therapy $(p=0.03)$. Conclusion: Contrast-enhancing meningeal lesions, systemic therapy, and radiotherapy were significantly associated with longer survival. Patients with contrast-enhancing lesions who were treated systemically had the longest survival. Evidence is increasing that systemic therapy plays an important role and should be applied in breast cancer patients with LM.

\section{Schlüsselwörter}

Mammakarzinom · Leptomeningeale Metastasen · Meningeosis carcinomatosa - Neoplastische Meningitis · Intrathekale Chemotherapie

\section{Zusammenfassung}

Hintergrund: Meningeosis carcinomatosa ist eine sehr ernst zu nehmende Verlaufsform fortgeschrittener Krebserkrankungen. Trotz aggressiver multimodaler Therapie ist das mediane Überleben sehr kurz. Methoden: Die Daten aller Mammakarzinompatientinnen mit Meningeosis carcinomatosa wurden retrospektiv analysiert $(n=27)$. Ergebnisse: Das mediane Überleben betrug 9 Wochen. Patienten mit kontrastmittelaufnehmenden meningealen Läsionen ( $n=11)$, die durch MRT entdeckt wurden, hatten ein medianes Überleben von 33 Wochen versus 8 Wochen bei Patienten, die diese Läsionen nicht aufwiesen ( $n=9 ; p=0,0407)$. Patienten, die eine systemische Therapie erhielten $(n=18)$, hatten ein medianes Überleben von 15 Wochen versus 7 Wochen ( $n=9 ; p=0,0106$ ). Patienten, die bestrahlt wurden $(n=8)$, hatten ein medianes Überleben von 17 Wochen versus 5 Wochen ( $n=18 ; p=0,0188$ ). In einer multiplen Cox-Regressionsanalyse stellten sich die Abwesenheit einer systemischen Therapie (Hazard Ratio, HR 89,5; $p=0,002$ ) und ein negativer Hormonrezeptorstatus (HR 4,2; $p=0,027$ ) als Risikofaktoren heraus. Zudem wurde im Interaktionsmodell kontrastmittelspeichernde Läsion als Effektmodifizierer für die systemische Therapie identifiziert $(p=0,03)$. Schlussfolgerung: Kontrastmittelaufnehmende meningeale Läsionen, systemische Therapie und Strahlentherapie waren signifikant mit einem längeren Überleben assoziiert. Patienten mit kontrastmittelaufnehmenden Läsionen, die systemisch behandelt wurden, hatten das längste Überleben. Wir können weitere Hinweise dafür liefern, dass systemische Therapie bei Brustkrebs-induzierter Meningeosis carcinomatosa wirksam ist und daher Bestandteil des multimodalen Behandlungskonzepts sein sollte.

\begin{tabular}{ll}
\hline KARGER & @ 2008 S. Karger GmbH, Freiburg \\
Fax +49 7614520714 & Accessible online at: \\
$\begin{array}{l}\text { E-mail Information@Karger.de } \\
\text { www.karger.com }\end{array}$ & www.karger.com/brc
\end{tabular}

\section{KARGER}

www.karger.com 


\section{Introduction}

Leptomeningeal metastasis (LM) is a devastating complication of advanced cancer. Despite aggressive therapy prognosis of patients is very limited with a median survival of several weeks or months only. The incidence in breast cancer is $3-5 \%$ and appears to be increasing [1] partly due to longer survival because of more effective therapies and to earlier diagnosis because of higher awareness and widespread use of MRI. In addition cerebrospinal fluid (CSF) is a sanctuary for many chemotherapeutical agents which cannot cross the intact blood-CSF barrier, hence allowing CNS relapse.

Standard therapy comprises radiation of symptomatic lesions, intrathecal or intraventricular chemotherapy (hence referred to as intra-CSF therapy), and sometimes systemic treatment. While the role of intra-CSF therapy is not clear, there is increasing evidence of the efficacy of systemic therapy.

Many publications collected data from different tumor entities ignoring the vastly different biological properties of these carcinomas. To exclude these differences, our study focussed on LM in breast cancer only. As previously described [2-4], $15-30 \%$ of patients survive 6 months or longer. This subgroup of patients has not been well described yet. Therefore, we compared these patients with those who survived less than 6 months. Survival data was analyzed in order to define possible prognostic factors and to evaluate the impact of systemic therapy on LM of breast cancer patients.

\section{Patients and Methods}

Study Population

We retrospectively analyzed all breast cancer patients diagnosed with LM between 1998 and 2005 at the Department of Oncology of University Hospital Charité Berlin, Germany. Collected data included age, time of diagnosis of primary tumor, time of first metastasis, primary TNM stage, histology of primary tumor, grading, localization of metastasis, number of previous systemic therapies, status of systemic disease, Karnofsky performance status (KPS), CSF findings, available neuroimaging findings (MRI), neurological signs and symptoms, and treatment for LM (intraCSF chemotherapy, radiation, systemic therapy).

The diagnosis of LM was based on malignant cells in CSF or typical MRI findings with neurological signs or symptoms or both. CSF was collected by lumbar puncture. Cytology, protein level, lactate, and glucose were analyzed routinely. Neurological examinations were done on the same day as initial lumbar puncture and thereafter repeated approximately every 2 weeks. Neuroimaging findings were divided into diffuse leptomeningeal contrast enhancement and nodular contrast-enhancing deposits in the subarachnoid space.

Neurological signs and symptoms were categorized as related to the cerebrum, cranial nerves, or spinal cord. Cerebral symptoms comprised headaches, nausea, vomiting, confusion, seizures, and mental status changes. Most frequently cranial nerves III, IV, and VI were impaired with ptosis and diplopia, but other cranial nerve symptoms such as visual impairment and facial paresthesia were also observed. Spinal symptoms consisted of pain, sensory deficits, and cauda equina syndrome.

\section{Therapy}

All available data on therapy was collected. Methotrexate (MTX), thiotepa, and liposomal cytarabine were used as intra-CSF therapy. MTX
Table 1. Pretreatment data of 27 breast cancer patients with leptomeningeal metastasis (LM)

\begin{tabular}{|c|c|c|}
\hline & $\begin{array}{l}\text { Median } \\
\text { (range) }\end{array}$ & $\begin{array}{l}\text { Patients, } \\
\mathrm{n}(\%)\end{array}$ \\
\hline Age at diagnosis of LM, years & $50(31-76)$ & \\
\hline \multicolumn{3}{|l|}{ Time from diagnosis of breast cancer to } \\
\hline 1st metastasis, months & $27(0-149)$ & \\
\hline Time from 1st metastasis to LM, months & $14(0-89)$ & \\
\hline \multicolumn{3}{|l|}{ Histology } \\
\hline Invasive ductal & & $17(74)$ \\
\hline Invasive lobular & & $4(17)$ \\
\hline Others & & $2(9)$ \\
\hline Unknown & & 4 \\
\hline \multicolumn{3}{|l|}{ Hormone receptors } \\
\hline Positive & & $15(60)$ \\
\hline Negative & & $10(40)$ \\
\hline Unknown & & 2 \\
\hline \multicolumn{3}{|l|}{ Her2/neu } \\
\hline Positive & & $6(32)$ \\
\hline Negative & & $13(68)$ \\
\hline Unknown & & 8 \\
\hline Number of metastatic sites at diagnosis of LM & $3(1-8)$ & \\
\hline Visceral metastasis & & $17(63)$ \\
\hline Soft tissue metastasis & & $17(63)$ \\
\hline Bone metastasis & & $19(70)$ \\
\hline Brain metastasis & & $14(52)$ \\
\hline \multicolumn{3}{|l|}{ Number of palliative chemotherapy lines } \\
\hline prior to $\mathrm{LM}$ & $2(0-5)$ & \\
\hline \multicolumn{3}{|l|}{ Activity of systemic disease at diagnosis of LM } \\
\hline No evidence of systemic disease & & 0 \\
\hline Remission or stable disease & & $4(15)$ \\
\hline Progressive disease & & $22(81)$ \\
\hline Unknown & & 1 \\
\hline \multicolumn{3}{|l|}{ Karnofsky performance score } \\
\hline$<70 \%$ & & $13(48)$ \\
\hline$\geq 70 \%$ & & $14(52)$ \\
\hline
\end{tabular}

was used in a dosage of 10-15 mg twice weekly, thiotepa $10 \mathrm{mg}$ twice weekly, and liposomal cytarabine $50 \mathrm{mg}$ every 2 weeks. Thiotepa and liposomal cytarabine were used as second-line therapy after progression under MTX. For systemic therapy anthracyclines, taxanes, vinorelbine, capecitabine, and an aromatase inhibitor were used.

\section{Statistical Analysis}

Statistical analysis was performed using commercially available software (SPSS 12). Descriptives include absolute and relative frequencies for categorial data, and median and range for numerical measurements.

Analyses with regard to time to death used Kaplan-Meier presentation and the logrank test in the univariate setting. For confirmatory analysis, potential predictors for survival time, i.e. factors having univariate $\mathrm{p}$-values equal or less than 0.05 , were included into a multiple Cox regression analysis with forward and backward selection. Additionally, an interaction term between systemic therapy and enhancing lesion condition was modelled into the selection process, in order to investigate if the presence of enhancing lesions represented a risk-modifying effect on systemic therapy. Only those 19 patients with information regarding all variables under consideration were included into this multivariate analysis.

Comparisons with respect to the group of long-time survivors were performed with Fisher's exact test to take account for the small number of patients. P-values for these explorative analyses are presented without Bonferroni correction. 


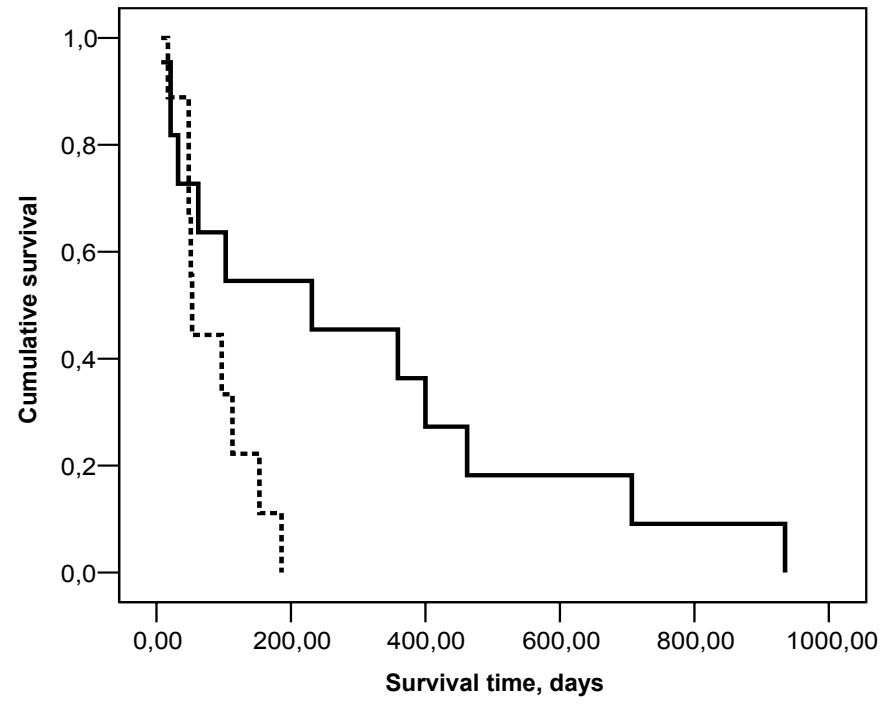

Fig. 1. Overall survival in groups of patients with $(n=11)$ and without $(n$ = 9) contrast-enhancing lesions detected in MRI ( $p=0.0407)$. Solid line: enhancing lesion; dotted line: no enhancing lesion.

\section{Results}

Twenty-seven female breast cancer patients with LM were identified between 1998 and 2005 at the Department of Oncology, University Hospital Charité Berlin, Germany. Patient characteristics are listed in table 1.

Presenting signs and symptoms were categorized as cerebral, cranial nerve dysfunction, and spinal. $63 \%$ of the patients had cerebral signs and symptoms, $44 \%$ cranial nerve involvement, and $41 \%$ spinal signs and symptoms. 13 patients had symptoms in only 1 region, 9 patients in 2, and 3 in 3 regions. In $81 \%(21 / 26)$ of the patients malignant cells in the CSF were detected in the first lumbar puncture. Except for one, cytology-negative patients showed other CSF abnormalities such as elevated protein or lactate in the first lumbar puncture. Of the 5 cytology-negative patients, CSF drawing was repeated in 4. In one patient cytology became positive in the second puncture, in the other 3 patients CSF remained cytology-negative. MRI was performed in 20 patients. Meningeal enhancement was seen in 15 patients, and contrast-enhancing lesions were seen in 11.

Systemic chemotherapy was concomitantly administered in 18 patients. The palliative systemic regimen was changed after diagnosis of LM in 14 patients. In all of these patients, disease was also progressive. Chemotherapy comprised of monotherapy with vinorelbine, taxanes, doxorubicin or capecitabine. One patient was systemically treated with an aromatase inhibitor only, she subsequently survived for more than 16 months.

\section{Survival Analysis}

Median survival after diagnosis of LM was 9 weeks. Patients with contrast-enhancing lesions detected by MRI $(\mathrm{n}=11)$ had

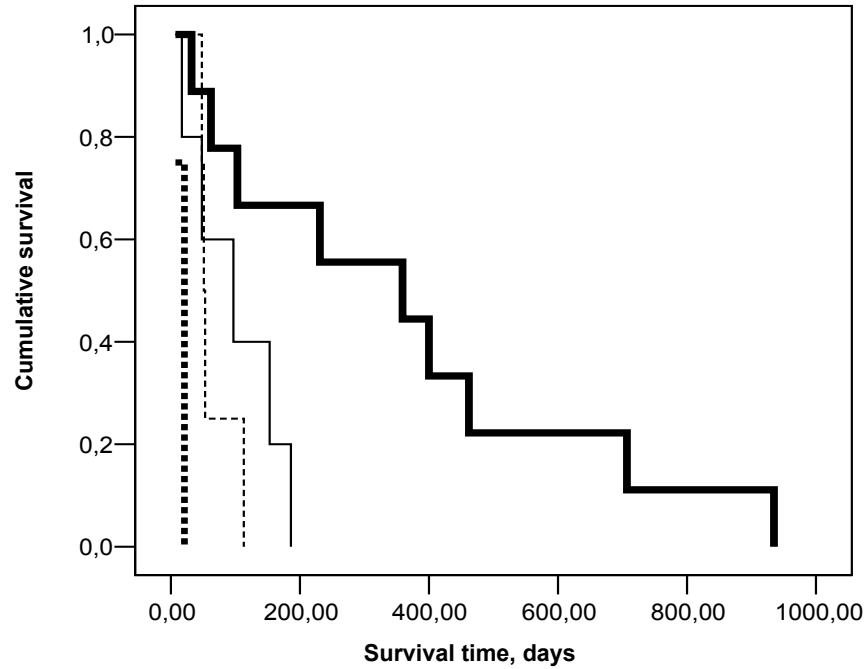

Fig. 2. Overall survival in the four groups of patients in the interaction model: meningeal lesion and systemic therapy. Patients with contrast-enhancing lesions profited most from systemic therapy, whereas contrast-enhancing lesion had no benefit in the group of patients who were not treated systemically. Bold solid line: systemic therapy, enhancing lesion; bold dotted line: systemic therapy, no enhancing lesion; thin solid line: no systemic therapy, enhancing lesion; thin dotted line: no systemic therapy, no enhancing lesion.

a median survival of 33 weeks, whereas patients without such lesions $(\mathrm{n}=9)$ had a median survival of only 8 weeks (fig. 1; $\mathrm{p}=0.0407)$. Patients who received systemic therapy $(\mathrm{n}=18)$ had a median survival of 15 weeks versus 7 weeks for those who did not receive systemic therapy $(\mathrm{n}=9 ; \mathrm{p}=0.0106)$. Patients with radiotherapy $(\mathrm{n}=8)$ had a median survival of 17 weeks as compared to 5 weeks for patients without radiotherapy $(\mathrm{n}=18 ; \mathrm{p}=0.0188)$. Patients with hormone receptorpositive tumors $(\mathrm{n}=15)$ survived 22 weeks versus 7 weeks in patients with hormone receptor-negative tumors $(n=10$; $\mathrm{p}=0.053)$.

All other potential predictors for survival time (age, histology, grading, HER2-neu, CSF parameters, site of symptoms, KPS, status of systemic disease) produced p-values greater than 0.05 in the analysis.

For confirmatory analysis, contrast-enhancing lesion, hormone receptor status, systemic therapy, and radiotherapy were selected as variables, and a multiple Cox regression analysis was performed, including the four main effects and, in order to identify potential effect modification on therapy through enhancing lesion, the interaction term 'enhancing lesion* systemic therapy' into the model.

After both backward and forward selection, lack of systemic therapy (hazard ratio, HR 89.5; $\mathrm{p}=0.002$ ) and negative hormone receptor status (HR 4.2; $\mathrm{p}=0.027$ ) emerged as significant main risk factors, together with enhancing lesion as risk modifier for systemic therapy (fig. 2 ; multivariate $\mathrm{p}=0.030$ ). This means that patients with enhancing lesions profited most 
from systemic therapy, whereas systemic therapy had no benefit in the group of patients with no enhancing lesions. Systemically treated patients with no enhancing lesions tended to fare even worse than those patients without systemic therapy at all (fig. 2; multivariate $\mathrm{p}=0.030$ ). In figure 2, the Kaplan-Meier presentation for the four groups, with/without systemic therapy and with/without contrast-enhancing lesion, is displayed.

\section{Long-Time Survivors}

In our analysis, 8 patients (29\%) survived for more than 6 months and $5(22 \%)$ for more than 12 months. In order to characterize these patients more accurately we compared long-time survivors ( $>6$ months) with those who survived less than 6 months. Contrast-enhancing meningeal lesions as detected by MRI were seen in 6 of 7 long-time survivors versus 5 of 13 short survivors $(\mathrm{p}=0.043)$. All long-time survivors were treated with systemic chemotherapy (8/8) versus only 10 of 19 short survivors $(\mathrm{p}=0.017)$. Lactate in initial CSF was within normal limits in 3 of 6 long-time survivors versus 1 of 15 short survivors $(p=0.022)$. Only 1 of 8 long-time survivors was hormone receptor negative versus 9 of 17 short survivors $(\mathrm{p}=0.054)$.

\section{Toxicity}

Toxicity data was available in 20 patients only. Arachnoiditis was present in 3 patients, with symptoms completely resolving under dexamethasone therapy. Three of 4 patients in whom an intraventricular device (Rickham reservoir) was implanted developed reservoir-related adverse events. In one patient leakage of CSF occurred, in one patient the tip of the catheter was misplaced into the brain parenchyma, and 2 patients developed bacterial meningitis, which was efficiently treated with systemic antibiotics. Leukoencephalopathy was seen in 2 of the $8(25 \%)$ long-time survivors and was accompanied with severe dementia. In another long-time survivor mild dementia was present, but no imaging study was undertaken. Two patients developed systemic toxicity after intraventricular MTX (thrombopenia, mucositis); both patients were heavily pretreated with chemotherapy. One patient had a singular episode of a grand mal seizure followed by a transient aphasia and agraphia after the fifth intra-CSF MTX application. However, this was completely reversible, and after 3 days the patient had normal neurological functions. MTX therapy was discontinued.

\section{Discussion}

Leptomeningeal metastasis is a rare manifestation of breast cancer, and available data has mainly been collected in retrospective studies such as ours. Only few randomized and prospective data have been published. Many publications collected data from different tumor entities ignoring the different biological properties of these tumors.
Despite unsatisfying evidence most patients are treated in a multimodality approach with radiation, intra-CSF chemotherapy, and systemic therapy. The rationale to deliver chemotherapy directly into the subarachnoid space is derived from the insufficient ability of most chemotherapeutical drugs to penetrate the intact blood-CSF barrier [5, 6]. However, an altered blood-CSF barrier with improved penetration of drugs has been described in animal models of LM [7, 8]. As an increased protein level in the CSF and meningeal contrast enhancement in MRI [9] - both commonly seen in LM - are signs for a disrupted blood-CSF barrier, it can be hypothesized that there is a sufficient drug concentration in the subarachnoid space after systemically administered therapy in LM patients with disrupted blood-CSF barrier.

Different pathological types of LM have been described. Thin coating of the meninges (sometimes only as single layer) is often seen in leukemic and lymphomatous meningitis, whereas metastatic nodules predominate in solid tumors [10]. These nodular lesions are contrast enhancing, which is a sign for blood-CSF barrier disruption. There is also increasing evidence of neovascularization of such lesions, as vascular endothelial growth factor (VEGF) was detected in CSF of LM patients [11-14]. VEGF is a potent inducer of neovascularization but also of vascular permeability [15], therefore potentially contributing to the disruption of the blood-CSF barrier. The above-mentioned different pathological tumor subtypes might contribute to the different therapeutic efficacy of intraCSF therapy in leukemic and lymphomatous meningitis as compared to solid tumor meningitis. Intra-CSF therapy penetrates only the superficial layers of the tumor [16], therefore contrast-enhancing lesions might not be treated efficiently with this local therapy. On the other hand, systemic therapy reaches the whole nodule because of the tumor's own blood supply as well as the impaired blood-CSF barrier. This might explain why in our series as well as in the series of Herrlinger et al. [17] the presence of contrast-enhancing lesions is a good prognostic factor in systemically treated patients.

To our knowledge there is only one published prospective randomized trial comparing intra-CSF treatment with non-intraCSF treatment [18]. However, there is increasing evidence that systemic therapy might be efficacious in LM. In the randomized trial, LM patients with breast cancer were treated with appropriate systemic chemotherapy and radiation, with or without intra-CSF chemotherapy. Boogerd et al. [18] found a median survival of 18 weeks in the intra-CSF-treated patients $(\mathrm{n}=17)$ and of 30 weeks for the non-intra-CSF group $(\mathrm{n}=18)$. This did not reach significance due to the small number of patients. Treatment toxicity occurred in $47 \%$ of the intra-CSF group and only in $6 \%$ of the non-intra-CSF group $(\mathrm{p}=0.0072)$. Previously similar results of nonrandomized studies have been published [4, 19, 20].

Bokstein et al. [2] retrospectively compared two groups of LM patients that differed only in the application of intra-CSF therapy. Both groups were treated with radiation if necessary and 
systemic chemotherapy, with one group additionally being treated with MTX intraventricularly and the other not receiving any intra-CSF therapy. Both groups did not significantly differ in median survival or in the proportion of long-time survivors. However, early neurological toxicity was described in $31 \%$ and late toxicity (leukoencephalopathy) in $20 \%$ of intraCSF-treated patients, with no neurological toxicity in the second group.

In many studies, including ours, patients who received systemic therapy had better outcomes. Grant et al. [21] described a median overall survival of 20 weeks for intravenously treated breast cancer patients compared to 3 weeks for patients without intravenous treatment. Herrlinger et al. [17] reported that systemic chemotherapy was highly significantly associated with longer survival in patients with contrast-enhancing meningeal lesions and in patients with systemic tumor. Fizazi et al. [3] also identified concomitant systemic chemotherapy as a positive prognostic factor for breast cancer patients. There is also a wealth of case reports of patients who have been successfully treated with systemic therapy [22-25]. Many other studies did not analyze the influence of systemic chemotherapy although some patients received systemic therapy and others did not [26-28].

In summary, there remain many questions about the best therapeutic approach. Intra-CSF therapy is an invasive procedure and, with the exception of liposomal cytarabine, the need for twice-weekly injections poses a disadvantage in this palliative setting. In addition, repeated intra-CSF therapy has considerable toxicity $[29,30]$. Arachnoiditis, the most frequent adverse event, comprises headaches sometimes accompanied by dizziness and nausea and is generally easily manageable with corticosteroids. However, late toxicity such as leukoencephalopathy is very often irreversible and occurs in up to $50 \%$ of the long-time survivors $[2,4,19]$. This risk is augmented by radia- tion and MTX. We found cognitive dysfunctions in 38\% of our long-time survivors. Many patients develop severe and irreversible cognitive dysfunctions such as dementia, confusion, and memory loss.

In accordance with our series, $10-30 \%$ of the patients survive for longer than 6 months $[3,4,17,31]$. Only scarce information is available on the characteristics of these long-time survivors. In our series long-time survivors had a significantly higher incidence of contrast-enhancing meningeal lesions as seen in MRI, and all of them were treated systemically. In addition, most of them were hormone receptor positive. Boogerd et al. [4] reported that 10/12 patients who survived 6 months and longer had been treated with systemic therapy as compared to only 8/19 patients who survived 6 weeks to 6 months. Again, this is in accordance with our findings.

Due to the retrospective nature of this and other analyses there are restrictions interpreting the results. It is possible that patients surviving only a few days did not get the chance to receive systemic treatment, therefore introducing a survival bias and ultimately influencing the results.

LM shows a wide range of natural courses with most patients dying within a few weeks, regardless of aggressive therapy, and only a minority of patients surviving for more than 6 months. The current standard of treating every patient diagnosed with LM aggressively in a multimodality approach might still need to be corrected. In our opinion, systemic therapy is one of the mainstays of treatment strategy in breast cancer-related LM. On the other hand, the indication for intra-CSF therapy needs to be defined more precisely. A prospective clinical trial is urgently needed to help define the best therapeutic approach to LM including the role of intra-CSF and systemic chemotherapy. Because of the rarity of the disease this needs to be done in a multi-institutional, multinational design. Only with combined effort this can be successfully undertaken.

\section{References}

1 Taillibert S, Laigle-Donadey F, Chodkiewicz C, Sanson M, Hoang-Xuan K, Delattre JY: Leptomeningeal metastases from solid malignancy: a review. J Neurooncol 2005;75(1):85-99.

2 Bokstein F, Lossos A, Siegal T: Leptomeningeal metastases from solid tumors: a comparison of two prospective series treated with and without intracerebrospinal fluid chemotherapy. Cancer 1998;82 (9):1756-63.

-3 Fizazi K, Asselain B, Vincent-Salomon A, Jouve M Dieras V, Palangie T, Beuzeboc P, Dorval T, Pouillart P: Meningeal carcinomatosis in patients with breast carcinoma. Clinical features, prognostic factors, and results of a high-dose intrathecal methotrexate regimen. Cancer 1996;77(7):1315-23.

$\checkmark 4$ Boogerd W, Hart AA, van der Sande JJ, Engelsman E: Meningeal carcinomatosis in breast cancer. Prognostic factors and influence of treatment. Cancer 1991;67(6):1685-95.

$\checkmark 5$ Kerr JZ, Berg S, Blaney SM: Intrathecal chemotherapy. Crit Rev Oncol Hematol 2001;37(3): $227-36$.
6 Shapiro WR, Young DF, Mehta BM: Methotrexate: distribution in cerebrospinal fluid after intravenous, ventricular and lumbar injections. N Engl J Med 1975;293(4):161-6.

7 Siegal T, Sandbank U, Gabizon A, Mizrachi R, BenDavid E, Catane R: Alteration of blood-brain-CSF barrier in experimental meningeal carcinomatosis. A morphologic and adriamycin-penetration study. J Neurooncol 1987;4(3):233-42.

8 Ushio Y, Shimizu K, Aragaki Y, Arita N, Hayakawa T, Mogami H: Alteration of blood-CSF barrier by tumor invasion into the meninges. J Neurosurg 1981;55(3):445-9.

9 Freilich RJ, Krol G, DeAngelis LM: Neuroimaging and cerebrospinal fluid cytology in the diagnosis of leptomeningeal metastasis. Ann Neurol 1995;38(1): 51-7.

10 Sagar SM: Carcinomatous meningitis: it does not have to be a death sentence. Oncology (Williston Park) 2002;16(2):237-43; discussion 244, 249-50.
11 Stockhammer G, Poewe W, Burgstaller S, Deisenhammer F, Muigg A, Kiechl S, Schmutzhard E, Maier H, Felber S, Schumacher P, Gunsilius E, Gastl G: Vascular endothelial growth factor in CSF: a biological marker for carcinomatous meningitis. Neurology 2000;54(8):1670-6.

12 Reijneveld JC, Brandsma D, Boogerd W, Bonfrer JG, Kalmijn S, Voest EE, Geurts-Moespot A, Visser MC, Taphoorn MJ: CSF levels of angiogenesis-related proteins in patients with leptomeningeal metastases. Neurology 2005;65(7):1120-2.

13 van de Langerijt B, Gijtenbeek JM, de Reus HP Sweep FC, Geurts-Moespot A, Hendriks JC, Kappelle AC, Verbeek MM: CSF levels of growth factors and plasminogen activators in leptomeningeal metastases. Neurology 2006;67(1):114-9.

14 Herrlinger U, Wiendl H, Renninger M, Forschler H Dichgans J, Weller M: Vascular endothelial growth factor (VEGF) in leptomeningeal metastasis: diagnostic and prognostic value. Br J Cancer 2004;91(2): 219-24. 
15 Yancopoulos GD, Davis S, Gale NW, Rudge JS, Wiegand SJ, Holash J: Vascularspecific growth factors and blood vessel formation. Nature 2000;407 (6801):242-8.

16 Blasberg RG, Patlak C, Fenstermacher JD: Intrathecal chemotherapy: brain tissue profiles after ventriculocisternal perfusion. J Pharmacol Exp Ther 1975;195 (1):73-83.

17 Herrlinger U, Forschler H, Kuker W, Meyermann R, Bamberg M, Dichgans J, Weller M: Leptomeningeal metastasis: survival and prognostic factors in 155 patients. J Neurol Sci 2004;223(2): 167-78.

18 Boogerd W, van den Bent MJ, Koehler PJ, Heimans JJ, van der Sande JJ, Aaronson NK, Hart AA, Benraadt J, Vecht Ch J: The relevance of intraventricular chemotherapy for leptomeningeal metastasis in breast cancer: a randomised study. Eur J Cancer 2004;40(18):2726-33.

19 Siegal T, Lossos A, Pfeffer MR: Leptomeningeal metastases: analysis of 31 patients with sustained off-therapy response following combined-modality therapy. Neurology 1994;44(8):1463-9.

20 Glantz MJ, Cole BF, Recht L, Akerley W, Mills P, Saris S, Hochberg F, Calabresi P, Egorin MJ: High-dose intravenous methotrexate for patients with nonleukemic leptomeningeal cancer: is intrathecal chemotherapy necessary? J Clin Oncol 1998;16(4): 1561-7.

21 Grant R, Naylor B, Greenberg HS, Junck L: Clinical outcome in aggressively treated meningeal carcinomatosis. Arch Neurol 1994;51(5):457-61.

-22 Boogerd W, Dorresteijn LD, van der Sande JJ, de Gast GC, Bruning PF: Response of leptomeningeal metastases from breast cancer to hormonal therapy. Neurology 2000;55(1):117-9.

23 Ozdogan M, Samur M, Bozcuk HS, Sagtas E, Yildiz M, Artac M, Savas B Durable remission of leptomeningeal metastasis of breast cancer with letrozole: a case report and implications of biomarkers on treatment selection. Jpn J Clin Oncol 2003;33 (5):229-31.

24 Rogers LR, Remer SE, Tejwani S: Durable response of breast cancer leptomeningeal metastasis to capecitabine monotherapy. Neuro Oncol 2004;6 (1): 63-4.

25 Giglio P, Tremont-Lukats IW, Groves MD: Response of neoplastic meningitis from solid tumors to oral capecitabine. J Neurooncol 2003;65(2): 167-72.

26 Grossman SA, Finkelstein DM, Ruckdeschel JC, Trump DL, Moynihan T, Ettinger DS: Randomized prospective comparison of intraventricular metho-trexate and thiotepa in patients with previously untreated neoplastic meningitis. Eastern Cooperative Oncology Group. J Clin Oncol 1993;11(3):561-9.

27 Jayson GC, Howell A, Harris M, Morgenstern G, Chang J, Ryder WD: Carcinomatous meningitis in patients with breast cancer. An aggressive disease variant Cancer 1994;74(12):3135-41.

28 Jaeckle KA, Phuphanich S, Bent MJ, Aiken R, Batchelor T, Campbell T, Fulton D, Gilbert M, Heros D, Rogers L, O'Day SJ, Akerley W, Allen J, Baidas S, Gertler SZ, Greenberg HS, LaFollette S, Lesser G, Mason W, Recht L, Wong E, Chamberlain MC, Cohn A, Glantz MJ, Gutheil JC, Maria B, Moots P, New P, Russell C, Shapiro W, Swinnen L, Howell SB: Intrathecal treatment of neoplastic meningitis due to breast cancer with a slow-release formulation of cytarabine. Br J Cancer 2001;84(2): 157-63.

29 Siegal T: Toxicity of treatment for neoplastic meningitis. Curr Oncol Rep 2003; 5(1):41-9.

30 Chamberlain MC, Kormanik PA, Barba D: Complications associated with intraventricular chemotherapy in patients with leptomeningeal metastases. J Neurosurg 1997;87(5):694-9.

31 Balm M, Hammack J: Leptomeningeal carcinomatosis. Presenting features and prognostic factors. Arch Neurol 1996;53(7):626-32. 